\title{
The potential of 4D sonography in the assessment of fetal neurobehavior - multicentric study in high-risk pregnancies
}

\author{
Asim Kurjak ${ }^{1}$, Salwa Abo-Yaqoub², Milan \\ Stanojevic $^{1, *}$, Alin Basgul Yigiter ${ }^{3}$, Oliver Vasilj ${ }^{1}$, \\ Daniela Lebit ${ }^{4}$, Afaf Naim Shaddad ${ }^{2}$, Badreldeen \\ Ahmed $^{2}$, Zehra Nese Kavak ${ }^{5}$, Berivoj Miskovic ${ }^{1}$, \\ Radu Vladareanu ${ }^{4}$, Lara Spalldi Barisic ${ }^{1}$, Guillermo \\ Azumendi', Moayyad Younis ${ }^{2}$, Ritsuko K. Pooh ${ }^{7}$ \\ and Aida Salihagic Kadic ${ }^{8}$ \\ ${ }^{1}$ Department of Obstetrics and Gynecology, Medical \\ School University of Zagreb, Sveti Duh Hospital, \\ Zagreb, Croatia \\ 2 Department of Obstetrics and Gynecology, Women's \\ Hospital, Hamad Medical Corporation, Doha, Qatar \\ ${ }^{3}$ Istanbul Bilim University School of Medicine, European \\ Florence Nightingale Hospital \\ ${ }^{4}$ Department of Obstetrics and Gynecology, Elias \\ University Emergency Hospital, Bucharest, Romania \\ ${ }^{5}$ Department of Obstetrics and Gynecology, Marmara \\ University, Faculty of Medicine, Istanbul, Turkey \\ ${ }^{6}$ Clinica Gutenberg, Malaga, Spain \\ ${ }^{7}$ CRIFM Clinical Research Institute of Fetal Medicine \\ PMC, Osaka, Japan \\ ${ }^{8}$ Department of Physiology, School of Medicine, \\ University of Zagreb, Croatia
}

\begin{abstract}
\footnotetext{
*Corresponding author:

Dr. Milan Stanojevic, MD, PhD

Head of the Neonatology Unit

Sveti Duh Hospital

Sv. Duh 64

10000 Zagreb

Croatia

E-mail: milan.stanojevic@optinet.hr
}

Objective: An evolving challenge for obstetrician is to better define normal and abnormal fetal neurological function in utero in order to better predict antenatally which fetuses are at risk for adverse neurological outcome.

Patients and methods: Prenatal neurological assessment in high-risk fetuses using four-dimensional ultrasound applying the recently developed Kurjak antenatal neurodevelopmental test (KANET). Postnatal neurological assessment was performed using Amiel Tison's neurological assessment at term (ATNAT) for all live-borns and general movement (GM) assessment for those with borderline and abnormal ATNAT. Results: Inclusion criteria were met by 288 pregnant women in four centers of whom 266 gave birth to a live-born baby. It was revealed that 234 fetuses were neurologically normal, 7 abnormal and 25 borderline. Out of 7 abnormal fetuses ATNAT was borderline in 5 and abnormal in 2, whereas GM assessment was abnormal in 5 and definitely abnormal in 2 . Out of 25 KANET borderline fetuses, ATNAT was normal in 7 , borderline in 17 and abnormal in 1, whereas the GM assessment was as follows: normal optimal in 4, normal suboptimal in 20, and abnormal in 1. In summary, out of 32 borderline and abnormal fetuses ATNAT was normal in 7, borderline in 22 and abnormal in 3; GM assessment was normal optimal in 4, normal suboptimal in 20 , abnormal in 6 and definitely abnormal in 2 .

Conclusion: The sonographic test requires further studies before being recommended for wider clinical practice.

Keywords: Fetal behavior; neurological risk; prenatal neurological test; 4D ultrasound (4D US).

\section{Introduction}

The current and evolving challenge for investigators of obstetric ultrasonography is better understanding of fetal neurological function $[2,12]$. There are many functional neurological abnormalities, such as cerebral palsy $(\mathrm{CP})$ which are poorly understood [24]. This uncertainty regarding causation vitalizes plaintiff's attorneys throughout the world who attempt to relate these neurological abnormalities exclusively to intrapartum events, such as use of oxytocin, forceps deliveries and failure to perform a cesarean delivery [7, 24]. Whereas some cases are probably related to intrapartum events, in the majority this is not the case [7, 24].

An evolving challenge for the obstetrician is to better define normal and abnormal fetal neurological function in utero for better prediction of fetuses at risk for adverse neurological outcomes irrespective of intrapartum management $[4,5]$. Indeed, assessment of the integrity of the fetal nervous system is a major task in modern perinatal medicine. There are many reasons for that. One is the fact that $2-4$ per 1000 live-born infants are affected by $\mathrm{CP}$, with an incidence that is unchanged since 1951 in developed as well as in developing countries [3]. Further advancement in the analysis of fetal activity was the introduction of high quality threedimensional/four-dimensional ultrasound (3D/4D US) which allowed to carry out real-time observations with sufficient dynamics and good image resolution and to produce a new prenatal scoring test [19]. The parameters used in the test are products of previously conducted multicenter research in fetal neurobehavior assessed by 2D sonography combined with neonatal signs suggested by Amiel-Tison as overlapping cranial sutures and the neurological thumb $[1,17,26]$. Since 4D enabled the evaluation of face and small anatomic parts, the movements of mouth, eyes and fingers are enrolled in the test as special variables $[10,16,18]$. The potential of the test was investigated at four university departments after proper training. We report here on the preliminary results obtained in the high-risk group of patients, trying to distinguish normal fetal brain and neurodevelopmental alterations due to the early brain impairment occurring in utero. 
Table 1 Inclusion criteria [5, 6, 8, 11, 14, 15, 21, 22, 25].

\begin{tabular}{ll}
\hline Family history & $\begin{array}{l}\text { Previous child with cerebral palsy } \\
\text { Maternal condition }\end{array}$ \\
Diabetes mellitus type I and II, thyroid disease, preexistent hypertension, drug abuse, thrombophilia, \\
anemia, epilepsy
\end{tabular}

The objective of this study was to apply the new antenatal scoring system (KANET - Kurjak antenatal neurodevelopmental test) to fetuses from high-risk pregnancies for neurological disorders and to verify the results of the test by two neonatal neurological tests: the Amiel-Tison neurological assessment at term (ATNAT) and the general movements (GMs) test introduced by Prechtl [1, 19, 23].

\section{Patients and methods}

The study participants were women with singleton pregnancies between 20 and 38 weeks of gestation, recruited in out- and inpatient clinics of University Departments of Obstetrics and Gynecology in the General Hospital "Sveti Duh", Zagreb, Croatia, Marmara University Hospital, Istanbul, Turkey, University Hospital Bucharest, Romania, and Hamad Medical Center, Doha, Qatar.

This was a multicenter, prospective cohort study of 288 pregnant women meeting the inclusion criteria given in Table 1 . The distribution of participants throughout four centers is presented in Table 1.

The study was approved by the Local Ethical Committees of the four institutions. Each participant gave her informed consent.

Fetal behavior was assessed by 4D US. All 4D US examinations were performed by experienced operators using either the Voluson 730 Expert 11 (General Electric, USA) or Sonoline Antares (Siemens AG, Issaquah, USA) with transabdominal $5 \mathrm{MHz}$ transducer. The methods of assessment have been described elsewhere [19].

The KANET was used to assess fetal neurobehavior [19]. In this study, we used a slightly modified version of the previously described test with the same parameters and the different scoring scale which was from 0 to 2 (compared with the original score from 1 to 3 ). The KANET form is illustrated in Table 2. Table 3 was constructed arbitrarily, representing allocation of fetuses into three separate groups after the KANET assessment: $0-5$ points were considered abnormal; 6-13 borderline; $\geq 14$ normal.

All neonates underwent postnatal neurological assessment according to Amiel-Tison (ATNAT) at the age of 1-3 days [1]. After the assessment, infants were assigned as normal, borderline, or abnormal. Infants from the borderline and abnormal groups were assigned to the high-risk group for development of neurological impairment. In this group of infants, for the purpose of this preliminary study, Prechtl's GM were evaluated at the premature (28-36 postmenstrual weeks) and term (37-46 postmenstrual weeks) age [23]. It is planned to repeat the GM assessment at the writhing age (46-52 postmenstrual weeks) and fidgety age (54-60 postmenstrual weeks). After any assessment of GM infant was classified to one of the groups according to Hadders Algra: normal optimal, normal suboptimal, abnormal, and definitely abnormal [9]. To simplify the analysis, the infants who were normal optimal and normal suboptimal were considered as "normal" whereas infants who were abnormal were considered as borderline, and those who were definitely abnormal were considered as abnormal.

All infants were scheduled to be assessed by ATNAT screening test at $1,3,6,9,12,18$ months of corrected age, whereas final assessment was planned to be at the corrected age of 24 months. All infants who needed additional assessments like neuroimaging, electrophysiological, ophthalmologic, orthopedic or any other examination were followed according to the local availability. It was intended to make the final diagnosis of disabling or non-disabling $\mathrm{CP}$ at the corrected age of 24 months on the basis of child's ability to walk. Figure 1 presents postnatal assessment flow chart.

The primary outcome was the usefulness of KANET to identify fetuses from high-risk pregnancies at neurological risk. Due to relatively small sample size statistical analysis is at present impossible.

\section{Results}

The number of fetuses assessed in four centers with the results of the KANET score are given in Table 4, while outcome of fetuses after KANET assessment is presented in Table 5. Combined results from the KANET, ATNAT and general movement of the survivors is presented in Table 6 . As shown in Table 6, a total of 7 fetuses had abnormal KANET scores, and 25 fetuses were borderline, for 32 fetuses at neurological risk. Of the seven fetuses with an abnormal KANET, postnatal neurological assessment by Amiel Tison's method (ATNAT) revealed three newborns (arthrogryposis, vermis aplasia and neonate of the mother with a previous child with (P) out of seven fetuses to be abnormal, whereas four were considered normal (ventriculomegaly, preeclampsia, thrombophylia, oligohydramnios). Out of the 25 borderline KANET fetuses there were 22 borderline newborns by ATNAT, whereas three were normal (ventriculomegaly, intraamniotic infection, maternal thrombocytopenia). Those who were abnormal prenatally and normal postnatally had the following prenatal risk factors: ventriculomegaly, Dandy Walker syndrome, skeletal dysplasia, polyhydramnios, hydrocephaly, diabetes in pregnancy, non-immune hydrops, intraamniotic infection, IUGR, trisomy 21 , thrombocytopenia, thrombophylia, preeclampsia, achondroplasia, oligohydramnios. Out of the three abnormal neonates following ATNAT assessment, two had definitely abnormal Prechtl's premature GMs (arthrogryposis and vermis aplasia), and an additional six were considered abnormal (neonate of a mother with the previous child with CP, Dandy Walker syndrome, hydrocephaly, trisomy 21 , ventriculomegaly, nonimmune hydrops). The remaining 24 children had normal optimal or normal suboptimal GMs. 
Table 2 Kurjak Antenatal Neurological Screening Test [according to 19].

\begin{tabular}{llll}
\hline Sign & Score & & Sign score \\
\cline { 2 - 4 } & 0 & 1 & 2 \\
\hline $\begin{array}{l}\text { Isolated head } \\
\text { anteflexion }\end{array}$ & Abrupt & $\begin{array}{l}\text { Small range } \\
(0-3 \text { times of } \\
\text { movements })\end{array}$ & $\begin{array}{l}\text { Variable in full range, } \\
\text { many alternation }(>3 \\
\text { times of movements })\end{array}$
\end{tabular}

Cranial sutures and head circumference

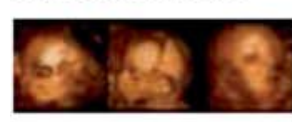

Isolated eye blinking

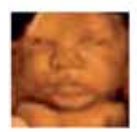

Facial alteration (grimace or tongue expulsion)

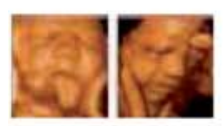

Mouth opening (yawning or mouthing)

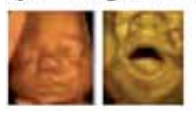

Isolated hand movememt

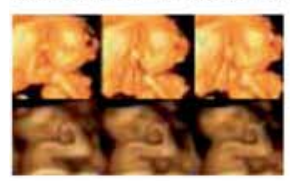

Isolated leg movement

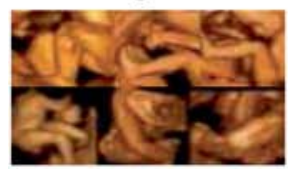

Hand to face movements

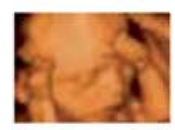

Finger movements

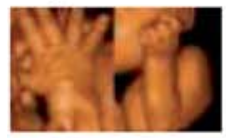

Gestalt perception of GMs
Overlapping of cranial suttures head circumference below or above the normal limit (-2 SD) according to GA

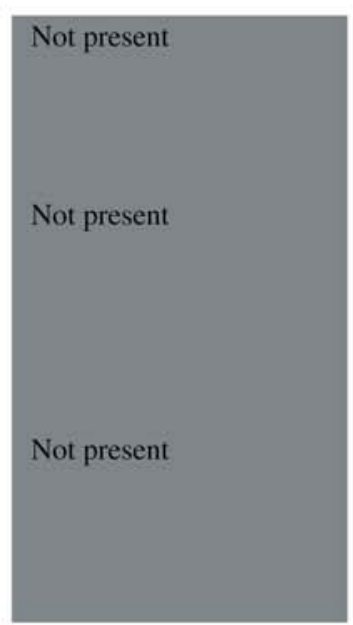

Not fluent (1-5 times of blinking)

Not fluent (1-5 times of alteration)

Not fluent (1-3 times of alteration)

Cramped

Poor repertoire

Cramped

Poor repertoire

Abrupt

Small range (0-5 times of movement)

Cramped invariable finger movements or bilateral clenched fist (neurological thumb)

Definitely abnormal
Variable and complex

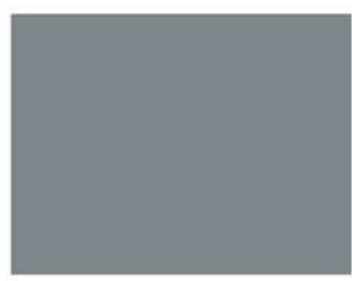

Fluency

(>5 times of blinking)

Fluency

( $>5$ times of alteration)

Fluency

( $>3$ times of alteration)

Variable and complex

Variable in full range, many alternation $(>6$ times of movements)

Smooth and complex, variable finger movements

Normal 
Table 3 Allocation of fetuses according to Kurjak's antenatal neurological screening test.

\begin{tabular}{ll}
\hline Total score & Interpretation \\
\hline $0-5$ & Abnormal \\
$6-13$ & Borderline \\
$14 \geq 19$ & Normal \\
\hline
\end{tabular}

\section{Discussion}

Despite medical reports from 100 years ago and 25 years of systematic research initiated by Prechtl and DeVries, the study of fetal neurobehavior is still in its infancy [4, 23]. There were attempts to develop a prenatal neurological screening test based on 2D ultrasound [13, 20]. The test was based on quantifying the fetal movements and did not consider the quality and variability of the movements $[13,20]$.
Table 4 The number of fetuses assessed in four centers with the results of the KANET score.

\begin{tabular}{lcccc}
\hline Center & $\begin{array}{l}\text { Number of } \\
\text { fetuses }\end{array}$ & \multicolumn{3}{c}{$\begin{array}{c}\text { Prenatal neurological assessment } \\
\text { (KANET) }\end{array}$} \\
\cline { 3 - 5 } & & Normal & Borderline & Abnormal \\
\hline Doha & 58 & 39 & 11 & 8 \\
Bucharest & 68 & 62 & 5 & 1 \\
Istanbul & 45 & 34 & 5 & 6 \\
Zagreb & 117 & 105 & 9 & 3 \\
Total & 288 & 240 & 30 & 18 \\
\hline
\end{tabular}

KANET $=$ Kurjak antenatal neurodevelopmental test.

The facial expressions were not included in these tests since they can only be clearly visualized by 4D US [13, 20]. The duration of the test was from 30 to $60 \mathrm{~min}$ and was not practical for daily use $[13,20]$. In the most comprehensive

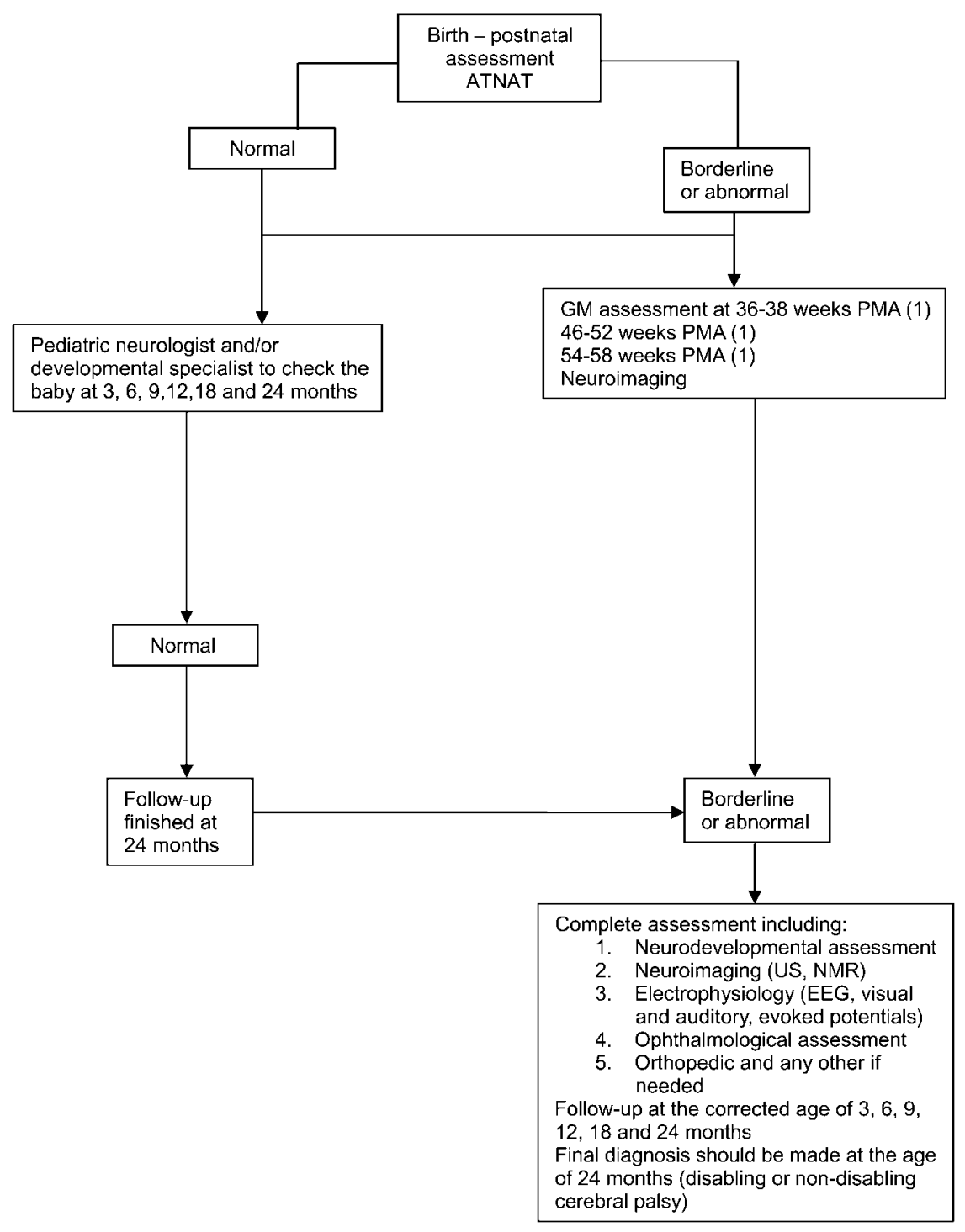

Figure 1 Postnatal assessment (flowchart). 
Table 5 Combined results from the KANET, ATNAT and general movement assessment.

\begin{tabular}{|c|c|c|c|c|c|c|}
\hline \multirow{2}{*}{\multicolumn{2}{|c|}{$\begin{array}{l}\text { Results of postnatal general } \\
\text { movements (GMs) }\end{array}$}} & \multicolumn{3}{|c|}{$\begin{array}{l}\text { Postnatal neonatal neurological } \\
\text { assessment (ATNAT) }\end{array}$} & \multicolumn{2}{|c|}{$\begin{array}{l}\text { Prenatal assessment } \\
\text { (KANET) }\end{array}$} \\
\hline & & \multirow{2}{*}{$\begin{array}{l}\text { Normal } \\
3\end{array}$} & \multirow{2}{*}{$\frac{\text { Borderline }}{1}$} & \multirow{2}{*}{$\begin{array}{l}\text { Abnormal } \\
0\end{array}$} & \multirow{2}{*}{$\begin{array}{l}\text { Borderline } \\
4\end{array}$} & \multirow{2}{*}{$\frac{\text { Abnormal }}{0}$} \\
\hline Normal optimal & 4 & & & & & \\
\hline Normal suboptimal & 20 & 4 & 16 & 0 & 20 & 0 \\
\hline Abnormal & 6 & 0 & 5 & 1 & 1 & 5 \\
\hline Definitely abnormal & 2 & 0 & 0 & 2 & 0 & 2 \\
\hline Total & 32 & 7 & 22 & 3 & 25 & 7 \\
\hline
\end{tabular}

KANET $=$ Kurjak antenatal neurodevelopmental test, ATNAT $=$ Amiel Tison's neurological assessment at term.

Table 6 Outcome of fetuses after KANET assessment.

\begin{tabular}{lclrc}
\hline KANET score & Terminated & Died & Alive & Total \\
\hline $0-5$ & 5 & 6 & 7 & 18 \\
$6-13$ & 2 & 3 & 25 & 30 \\
$\geq 14$ & 6 & 0 & 234 & 240 \\
Total & 13 & 9 & 266 & 288 \\
\hline
\end{tabular}

KANET $=$ Kurjak antenatal neurodevelopmental test.

review on fetal behavior that included 109 papers, the authors concluded that future studies of fetal behavior have to focus on spontaneous fetal movements and GMs [4]. It was stressed that the new 4D US technology could be the tool enabling new insight into fetal neurobehavior [4]. The implementation of these new diagnostic data increased our knowledge about central nervous system development [2]. Furthermore, the traditional concept that brain damage is caused during birth or early neonatal period has been challenged when antenatal and unclassifiable factors are now considered as the most important etiological factors [7, 24].

The three illustrative cases with abnormal KANET scoring that we present are arthrogryposis, vermis aplasia, and a fetus whose previous sibling had verified CP. The fetuses in these three cases had especially reduced facial movements during repeated scans. Fetuses with vermis aplasia and arthrogryposis had normal cranial sutures but the isolated head flexion was small in range for both cases. Isolated hand movements, hand to face and leg movements were poor in repertoire for all three cases. The finger movements were cramped and invariable in all three cases. The Gestalt perception of GM was abnormal in all three cases. We also followed longitudinally the behavior of a fetus with acranius. The mother decided not to terminate the pregnancy due to religious reasons. It has been documented that the fetus at 20 weeks of gestation had hypertonic movements with high amplitude and high speed. The movements emerged abruptly with burst-paused patterns, the variability of head movements was missing, without changes of facial expressions. As the gestational age advanced and the motor control was shifting from lower to upper control center, the movement patterns changed as well. At gestational age of 32 weeks, the fetus had no facial expressions (face as a mask) and hand movement repertoire was very poor. At 36 weeks the absence of both facial expressions and limb movements was observed. The neonate died during labor.

It seems that some of the prenatal conditions are temporarily affecting fetal neurological status, having a tendency for improvement in neurological status after birth. On the basis of our preliminary results, we can only speculate that some fetuses are liberated after birth from numerous illdefined intrauterine constrains.

Our study shows that the new test might be useful in standardization of neurobehavioral assessments. Furthermore, there is a potential for antenatal detection of serious neurological problems. At this stage, the test separates serious structural anomalies associated with brain impairment (arthrogryposis, vermis aplasia, anencephaly). Most of the high-risk cases have been found with normal neurobehavior and that has been proven by experienced neonatologists. Understandable serious abnormalities with brain impairment and abnormal test have been detected earlier and terminated.

This is work in progress and four collaborating centers are continuing the investigation. In some of the centers (Doha, Zagreb) preliminary results have already been obtained after one year of life. The test requires further studies before being recommended for clinical practice. In the meantime the potential of antenatal scoring system should be neither overestimated nor underestimated.

\section{References}

[1] Amiel-Tison C. Update of the Amiel-Tison neurological assessment for the term neonate or at 40 weeks corrected age. Pediatr Neurol. 2002;27:196-212.

[2] Amiel-Tison C, Gosselin J, Kurjak A. Neurosonography in the second half of fetal life: a neonatologist's point of view. J Perinat Med. 2006;34:437-46.

[3] Clark SL, Hankin GDV. Temporal and demographic trends in cerebral palsy - fact and fiction. Am J Obstet Gynecol. 2003; 72:865-8.

[4] De Vries JIP, Fong BF. Normal fetal motility: an overview. Ultrasound Obstet Gynecol. 2006;27:701-11.

[5] De Vries JIP, Fong BF. Changes in fetal motility as a result of congenital disorders: an overview. Ultrasound Obstet Gynecol. 2007;29:590-9.

[6] Gingras JL, O'Donnell KJ. State control in the substanceexposed fetus. I. The fetal neurobehavioral profile: an assess- 
ment of fetal state, arousal, and regulation competency. Ann NY Acad Sci. 1998;846:262-76.

[7] Greenwood C, Newman S, Impey L, Johanson A. Cerebral palsy and clinical negligence litigaton: a cohort study. Br J Obstet Gynaecol. 2003;110:6-11.

[8] Habek D. Effects of smoking and fetal hypokinesia in early pregnancy. Arch Med Res. 2007;38:864-7.

[9] Hadders-Algra M. General movements: a window for early identification of children at high risk for developmental disorders. J Pediatr. 2004;145:S12-8.

[10] Hata T, Kanenishi K, Akiyama M, Tanaka H, Kimura K. Real-time 3-D sonographic observation of fetal facial expression. J Obstet Gynaecol Res. 2005;31:337-40.

[11] Hemminiki K, Xinjun L, Sundouist K. High familial risk for cerebral palsy implicate partial heritable aetiology. Paediatr Perinat Epidemiol. 2007;21:235-41.

[12] Hepper PG. Fetal behavior: why so sceptical? Ultrasound Obstet Gynecol. 1996;8:145-8.

[13] Horimoto N, Koyanagi T, Maeda H, Satoh S, Takashima T, Minami T, et al. Can brain impairment be detected by in utero behavioural patterns? Arch Dis Child. 1993;69:3-8.

[14] Jansson LM, Dipietro J, Elko A. Fetal response to maternal methadone administration. Am J Obstet Gynecol. 2005;193: 611-7.

[15] Kainer F, Prechtl HF, Engele H, Einspieler C. Assessment of the quality of general movements in fetuses and infants of women with type-I diabetes mellitus. Early Hum Dev. 1997; 50:13-25.

[16] Kozuma S, Baba K, Okai T, Taketani Y. Dynamic observation of the fetal face by three-dimensional ultrasound. Ultrasound Obstet Gynecol. 1999;13:283-4.

[17] Kurjak A, Andonotopo W, Hafner T, Salihagic A, Standojevic M, Azumendi G, et al. Normal standards for fetal neurobehavioral developments - longitudinal quantification by fourdimensional sonography. J Perinat Med. 2006;34:56-65.

[18] Kurjak A, Azumendi G, Andonotopo W, Salihagic-Kadic A. Three- and four-dimensional ultrasonography for the struc- tural and functional evaluation of the fetal face. Am J Obstet Gynecol. 2007;196:16-28.

[19] Kurjak A, Miskovic B, Stanojevic M, Amiel-Tison C, Ahmed B, Azumendi G, et al. New scoring system for fetal neurobehavior assessed by three- and four-dimensional sonography. J Perinat Med. 2008;36:73-81.

[20] Morokuma S, Fukushima K, Yumoto Y, Uchimura M, Fujiwara A, Matsumoto M, et al. Simplified ultrasound screening for fetal brain function based on behavioral pattern. Early Hum Dev. 2007;83:177-81.

[21] Mulder EJ, Morssink LP, van der Schee T, Visser GH. Acute maternal alcohol consumption disrupts behavioral state organization in the near-term fetus. Pediatr Res. 1998;44: 774-9.

[22] Parisi P, Francia A, Vancore N, Fiore S, Giallonrado AT, Manfredi M. Psychomotor development and general movements on offspring of women with epilepsy and anticonvulsant therapy. Early Hum Dev. 2003;74:97-108.

[23] Prechtl HFR. State of the art of a new functional assessment of the young nervous system. An early predictor of cerebral palsy. Early Hum Dev. 1997;50:1-4.

[24] Strijbis EMM, Oudman I, Van Essen P, MacLennan AH. Cerebral palsy and application of the international criteria for acute intrapartum hypoxia. Obstet Gynecol. 2006;107:135765.

[25] Warner J, Hains SM, Kisilevsky BS. An exploratory study of fetal behavior at 33 and 36 weeks gestational age in hypertensive women. Dev Psychobiol. 2002;41:156-68.

[26] Yigiter AB, Kavak ZN. Normal standards of fetal behavior assessed by four-dimensional sonography. J Matern Fetal Neonatal Med. 2006;19:707-21.

The authors stated that there are no conflicts of interest regarding the publication of this article.

Received June 9, 2009. Revised August 18, 2009. Accepted August 21, 2009. 